\title{
Perancangan Troli Ergonomi pada Aktivitas Pengangkutan Beras di Penggilingan Padi
}

\author{
Akh. Sokhibi ${ }^{1 *}$, Mia Ajeng Alifiana ${ }^{2}$, Muhammad Imam Ghozali ${ }^{3}$ \\ ${ }^{1}$ Program Studi Teknik Industri, Fakultas Teknik, Universitas Muria Kudus, Gondangmanis Bae Kudus, Jawa Tengah 59327 \\ Indonesia \\ ${ }^{2}$ Program Studi Manajemen, Fakultas Ekonomi dan Bisnis, Universitas Muria Kudus, Gondangmanis Bae Kudus, Jawa \\ Tengah 59327 Indonesia \\ ${ }^{3}$ Program Studi Teknik Informatika, Fakultas Teknik, Universitas Muria Kudus, Gondangmanis Bae Kudus, Jawa Tengah \\ 59327 Indonesia
}

\section{ARTICLE INFORMATION}

Article history:

Received: November 13, 2018

Revised: December 07, 2018

Accepted: April 00, 00

\section{Kata Kunci:}

Ergonomi

Posisi Kerja

Kelelahan

Troli

Keywords:

Ergonomics

Exhausted

Trolleys

Work Position

*Corresponding Author

Akh. Sokhibi

E-mail: akh.sokhibi@umk.ac.id

\section{A B S T R A K}

\begin{abstract}
Kaidah Ergonomi dalam penggilingan padi sering kali tidak digunakan. Pada penggilingan padi di Desa Kedungdowo Kecamatan Kaliwungi Kabupaten Kudus, posisi kerja pembawa beras dari corong luaran mesin giling padi menuju timbangan tidak mempertimbangkan aspek ergonomi karena membawa beras hanya dengan dipanggul. Hal ini dilakukan terus menerus sehingga cepat menimbulkan kelelahan dan ketidaknyamanan. Metode yang digunakan dalam penelitian ini adalah dengan pengukuran data antropometr dari pekerja pembawa beras. Data antropometri yang digunakan dalam penelitian ini adalah Tinggi Siku Berdiri (TSB) pekerja dan Diameter Genggam Tangan (DGT) pekerja. Data antropometri tersebut diolah dan diuj untuk dasar ukuran troli ergonomic yang akan dirancang. Hasil dari penelitian yang telah dilakukan adalah diperoleh rancangan troli ergonomi. dengan ukuran tinggi troli $100,81 \mathrm{~cm}$; diameter genggam tangan troli 4,77 $\mathrm{cm}$; panjang troli $71 \mathrm{~cm}$; dan lebar troli $52 \mathrm{~cm}$. Dari hasil kuisioner keluhan posisi kerja pekerja, diperoleh penurunan keluhan pada leher sebesar $11 \%$, pada lengan tangan sebesar $90 \%$, pada punggung sebesar $4 \%$, pada pinggang sebesar $8 \%$, pada paha sebesar $47 \%$, pada lutut sebesar $25 \%$, pada betis sebesar $17 \%$. setelah menggunakan troli ergonomi
\end{abstract}

\section{A B S T R A C T}

Ergonomics in rice milling does not use often. In Kedungdowo village, Kaliwungi Subdistrict, Kudus Regency, the working position of the rice hull machine to the scales did not take into account the ergonomic aspects because only rice was rice with a shoulder. This is done continuously fast and efficiently. The method used in this study is to measure anthropometric data from rice carrying workers. The anthropometric data in this study were worker elbow height (TSB) and hand held hand diameter (DGT). Anthropometric data is processed and edited for the ergonomic trolley base to be designed. The results of the research conducted were obtained by the ergonomic trolley concept. with a height of $100,81 \mathrm{~cm}$ trolley; diameter of electric hand trolley $4.77 \mathrm{~cm} ; 71 \mathrm{~cm}$ long trolley; and the width of the trolley is $52 \mathrm{~cm}$. From the results of the questionnaire, the profit that occurred on the neck was $11 \%$, in the hand round was $90 \%$, the back was $4 \%$, the waist was $8 \%$, the thigh was $47 \%$, the knee was $25 \%$, the calf was $17 \%$. after using ergonomic trolleys

\section{PENDAHULUAN}

Menurut data BPS, Indonesia sebagai negara agraris mempunyai luas baku sawah pada tahun 2018 mencapai 7,1 juta hektar yang tersebar di seluruh wilayah nusantara dengan berbagai macam jenis pangan yang khas bagi daerah masing-masing. Tanaman padi merupakan tanaman utama yang dijadikan sebagai kebutuhan primer (makanan pokok) bagi masyarakat Indonesia. Sedangkan untuk potensi panen padi pada tahun 2018 sebesar 10,9 juta hektar dan 
potensi produksi padi diperkirakan hanya 56,54 juta ton.

Penggilingan padi merupakan sebuah aktivitas untuk merubah padi menjadi beras. Proses merubah padi menjadi beras ini banyak dipengaruhi oleh faktor penunjang pada tempat penggilingan padi. Salah satu faktor penunjang dari berbagai faktor yang penting dalam proses penggilingan padi adalah faktor ergonomi. Ergonomi berfokus pada sistem dimana manusia berinteraksi dengan lingkungan fisik, lingkungan organisasi maupun lingkungan sosial [1]-[4] yang dapat diimplementasikan pada banyak kegiatan termasuk pada proses penggilingan padi. Penerapan konsep ergonomi secara konsisten mampu mengurangi kelelahan akibat kerja, meningkatkan kesehatan fisik, dan menciptakan efektivitas kerja yang berdampak pada peningkatan produktivitas kerja [5]-[7].

Salah satu aktivitas pada penggilingan padi yang harus memperhatikan faktor ergonomi adalah saat proses pekerja pengangkut beras menuju timbangan. Pada aktivitas ini terdapat permasalahan yaitu pekerja pengangkut beras membawa beras dengan dipanggul atau diangkat dengan tangan (Gambar 1). Hal ini jika dilihat dari aspek ergonomi, maka posisi kerja dan fasilitas kerja pada penggilingan padi tersebut tidak memenuhi aspek ergonomi. Jika hal ini dilakukan terus menerus, maka akan cepat menimbulkan kelelahan, ketidaknyamanan, risiko cedera, pembungkukan, dan penurunan waktu produktivitas.

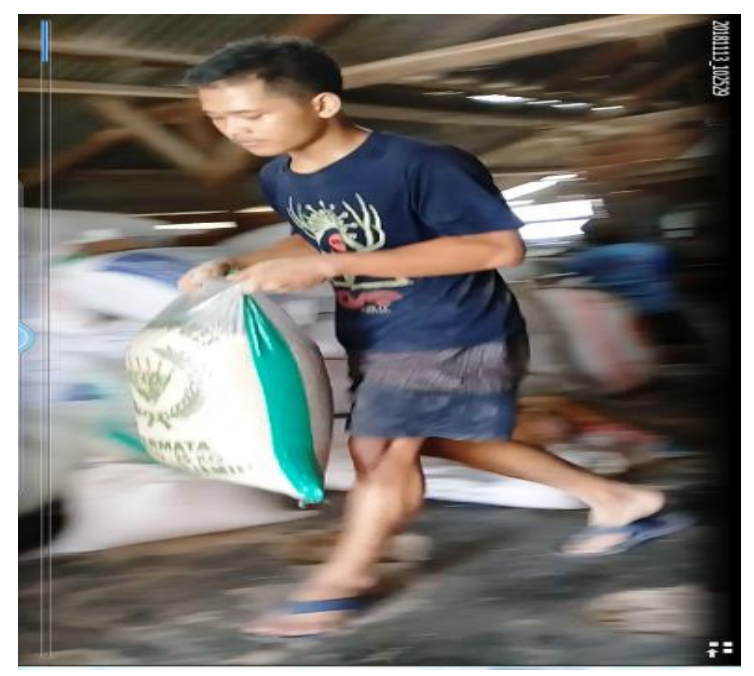

Gambar 1. Posisi Kerja

Literasi mengenai pembuatan alat bantu telah banyak dilakukan seperti perancangan alat bantu pada industri rumah makan [8], pekerja batik [9] dan pemindahan barang/produk [10]-[12], terutama pada kegiatan pemindahan karung pada proses penggilingan padi [13], [14] dengan menggunakan metode REBA dalam menganalis posisi kerja. Pada penelitian ini dasar perbaikan hanya berdasarkan hasil Kuisioner Standar Nordic Quistioner yang diterjemahkan dalam perhitungan antropometri. Penelitian ini bertujuan untuk melakukan perbaikan fasiltas kerja berupa perancangan troli ergonomi di Penggilingan Padi Desa Kedungdowo, Kecamatan Kaliwungu, Kabupaten Kudus" untuk mengurangi keluhan posisi kerja sehingga akan berdampak pada posisi kerja yang ergonomi.

\section{METODE PENELITIAN}

Metode yang digunakan dalam penelitian ini adalah pengukuran antropometri pada pekerja pengangkut beras. Antropometri dalam ergonomi berkaitan dengan perancangan bentuk dan ukuran suatu desain yang sesuai berdasarkan hasil pengukuran antropometri dan statistik deskriptif (paling umum mean dan standar deviasi) [15][17]. Data antropometri yang digunakan dalam penelitian ini adalah Tinggi Siku Berdiri (TSB) pekerja dan Diameter Genggam Tangan (DGT) pekerja. Data antropometri tersebut diuji (uji normalitas, uji keseragaman, uji kecukupan data) dan diolah dengan memperhatikan nilai persentil sebagai dasar perancangan trolley yang ergonomis.

Sampel penelitian ini berjumlah 30 responden dengan dasar bahwa jumlah sampel 30 sampai 300 merupakan jumlah yang tepat untuk kebanyakan penelitian [18]. Objek penelitian ini adalah aktivitas pekerja mengangkut atau memanggul beras yang keluar dari corong penggilingan padi menuju timbangan pada penggilingan padi Desa Kedungdowo, Kecamatan Kaliwungu, Kabupaten Kudus. Instrument yang digunakan dalam penelitian ini adalah lembar kuisioner Standar Nordic Quistioner (Gambar 2) pekerja pengangkut beras. Kuisioner Standar Nordic Quistioner dibagikan kepada pekerja dan konsumen penggiling padi yang berjumlah 29 orang sebelum dan sesudah menggunakan troli hasil perancangan pada penelitian ini. Konsumen penggiling padi dilibatkan dalam menilai kuisioner karena konsumen yang menggiling padi di desa Kedungdowo Kacamatan Kaliwungu Kabuapten Kudus ini umum nya mengambil atau mengangkut sendiri beras yang keluar dari corong penggilingan padi menuju timbangan. 
Standardised Nordic Questionnaires (SNQ)

\begin{tabular}{|c|c|}
\hline Masalah dengan Organ Gerak & Petuajuk dalam meajawab kuisioner \\
\hline & $\begin{array}{l}\text { Pada gambar di samping saudara bisa melihat kira-kira di posisi } \\
\text { bagian mana dari tubuh, saudara yang berkaitan dengan } \\
\text { kuisioner, saudara bisa mencntakan sendiri organ mana yang } \\
\text { pernah menjadi masalah bagi saudara (jika ada). }\end{array}$ \\
\hline$>$ & $\begin{array}{l}\text { Silahkan menjawab pertanyaan yang ada dengan memberi } \\
\text { tanda }(X) \text { pada kotak yang sestai untuk setiap pertanyaan. } \\
\text { Kami berharap saudara mau menjawab kuisioner ini meskipun } \\
\text { saudara tidak pernah mengalami masalah dengan bagian crgan } \\
\text { tubuh saudara }\end{array}$ \\
\hline
\end{tabular}

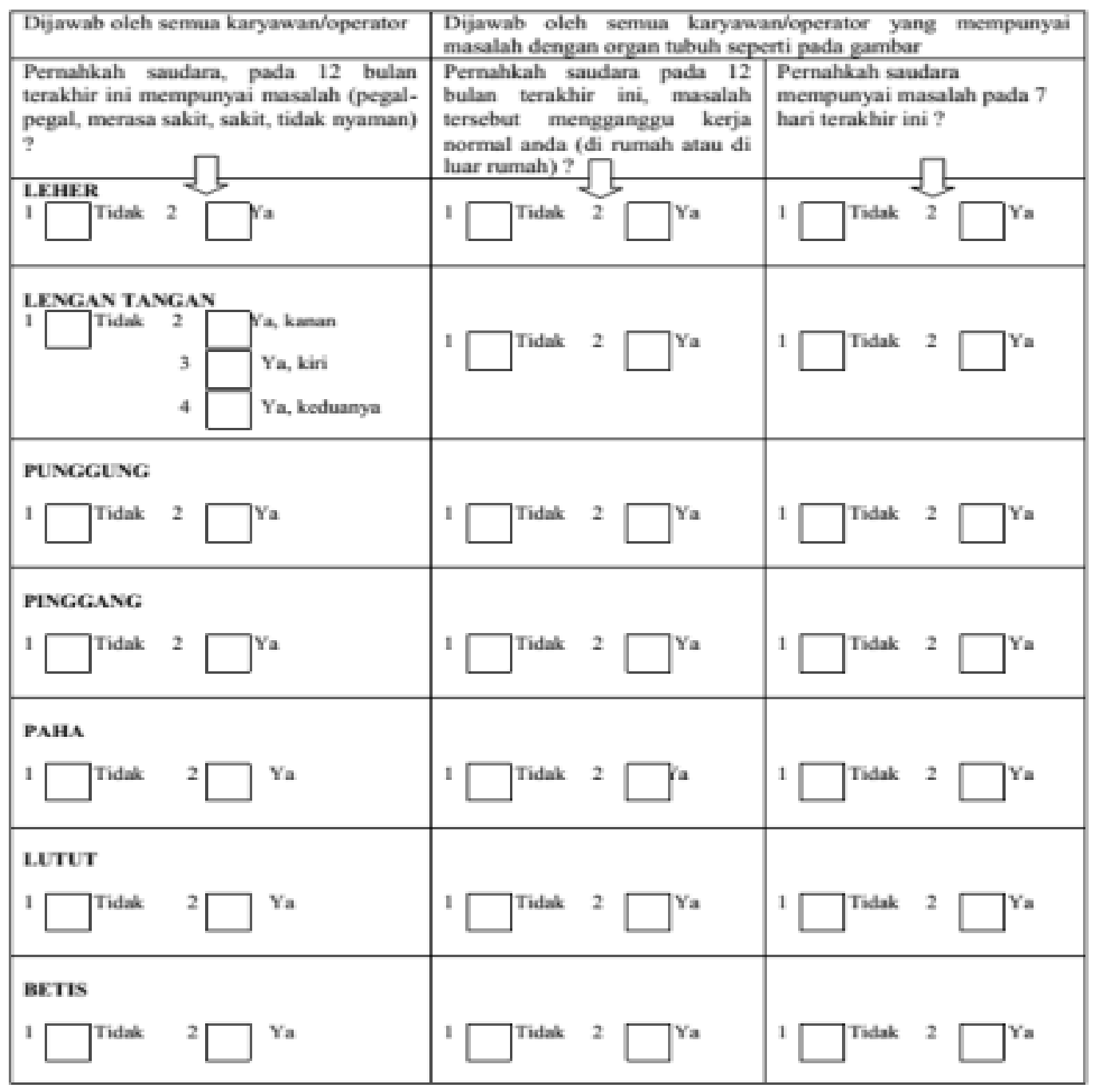

Gambar 2. Kuisioner Standar Nordic Questioner

\section{HASIL DAN PEMBAHASAN}

Hasil kuesioner Standar Nordic Quistioner awal diperoleh keluhan terbesar pekerja dan konsumen yang melakukan kegiatan pengangkutan adalah sakit pada punggung, leher ,dan pinggang (Tabel 1). Berdasarkan hasil kuisioner yang telah diperoleh maka dilakukan rancangan trolly yang dapat menurunkan beban kerja dengan memperhatikan tinggi siku berdiri dan diameter genggam tangan yang akan 
menggantikan peran anggota tubuh yang selama ini digunakan.

Tabel 1. Hasil Kuisioner awal

\begin{tabular}{lcc}
\hline Keluhan & Jumlah Keluhan & Persentase \\
\hline Punggung & 30 & $20,55 \%$ \\
Leher & 28 & $19,88 \%$ \\
Pinggang & 25 & $17,12 \%$ \\
Lutut & 20 & $13,70 \%$ \\
Betis & 18 & $12,33 \%$ \\
Paha & 15 & $10,27 \%$ \\
Lengan Tangan & 10 & $6,85 \%$ \\
\hline
\end{tabular}

Data Antropometri Pekerja

Data antropometri yang digunakan untuk perancangan troli ergonomi yaitu tinggi siku berdiri dan diameter genggam tangan. Tabel 1 berikut menunjukkan data antropometri pekerja dengan troli.

Tabel 1. Data Antropometri Pekerja

\begin{tabular}{llc}
\hline \multirow{3}{*}{ Pekerja } & Tinggi Siku & Diameter \\
& Berdiri $(\mathrm{cm})$ & $(\mathrm{cm})$
\end{tabular}

\begin{tabular}{ccc}
\hline 1 & 101 & 5 \\
2 & 103 & 6 \\
3 & 102 & 7 \\
4 & 104 & 6 \\
5 & 102 & 5 \\
6 & 105 & 5 \\
7 & 104 & 7 \\
8 & 103 & 5 \\
9 & 101 & 7 \\
10 & 102 & 7 \\
11 & 104 & 6 \\
12 & 106 & 5 \\
13 & 105 & 6 \\
14 & 106 & 6 \\
15 & 105 & 7 \\
16 & 104 & 6 \\
17 & 103 & 7 \\
18 & 105 & 6 \\
19 & 102 & 5 \\
20 & 103 & 7 \\
21 & 101 & 7 \\
22 & 102 & 6 \\
23 & 103 & 6 \\
24 & 104 & 5 \\
25 & 106 & 7 \\
26 & 105 & 6 \\
27 & 104 & 6 \\
28 & 102 & 5 \\
29 & 103 & 7 \\
30 & 103 & 6 \\
\hline & &
\end{tabular}

Data antropometri pekerja pengguna troli digunakan untuk menentukan tinggi troli dan diameter pegangan troli. Sedangkan untuk menentukan panjang alas troli dan lebar alas troli, digunakan ukuran dari panjang dan lebar karung wadah beras yaitu $71 \mathrm{~cm}$ untuk panjang karung beras dan $51 \mathrm{~cm}$ untuk lebar karung beras.

\section{Uji Normalitas Data Antropometri Pekerja}

Dilakukan dengan uji kolmogoriv-smirnov pada software SPSS. Data dikatakan normal apabila sig > a (maka $\mathrm{H}_{0}$ diterima), dimana $\mathrm{H}_{0}$ adalah Hipotesis data mengikuti distribusi normal. Dapat disimpulkan dari tabel 2 bahwa hasil uji normalitas pada tinggi siku berdiri adalah data normal, karena sig $>\alpha$ (maka $\mathrm{H}_{0}$ diterima). Sedangkan hasil uji normalitas pada diameter genggam tangan juga adalah data normal, karena sig $>\alpha$ (maka $\mathrm{H}_{0}$ diterima).

Tabel 2. Uji Normalitas Data Antropometri

\begin{tabular}{lccc}
\hline \multicolumn{1}{c}{ Data Antropometri } & N & Sig. & $\alpha$ \\
\hline Tinggi Siku Berdiri & 30 & 0,36 & 0,05 \\
$\begin{array}{l}\text { Diameter Genggam } \\
\text { Tangan }\end{array}$ & 30 & 0,11 & 0,05 \\
\hline
\end{tabular}

Uji Keseragaman Data Antropometri Pekerja Dilakukan dengan uji quality control pada software SPSS. Maka akan diketahui batas kontrol atas dan batas kontrol bawah. Data dikatakan seragam jika data berada pada batas kontrol atas dan batas kontrol bawah.

Tabel 3. Uji Keseragaman Data Antropometri

\begin{tabular}{|c|c|c|c|c|}
\hline $\begin{array}{c}\text { Data } \\
\text { Antropometri }\end{array}$ & $\bar{X}$ & $\sigma$ & BKA & BKB \\
\hline $\begin{array}{l}\text { Tinggi Siku } \\
\text { Berdiri }\end{array}$ & 103,17 & 1,44 & 107,85 & 98,99 \\
\hline $\begin{array}{l}\text { Diameter } \\
\text { Genggam } \\
\text { Tangan }\end{array}$ & 6,07 & 0,79 & 8,73 & 3,41 \\
\hline
\end{tabular}

Dari tabel 3 diketahui bahwa data tinggi siku berdiri dikatakan seragam karena data rata-rata sebesar 103,17 berada dalam BKA dan BKB. Demikian juga dengan data diameter genggam tangan dikatakan seragam karena data rata-rata sebesar 6,07 berada dalam BKA dan BKB. Gambar 3 dan Gambar 4 menunjukkan hasil uji keseragaman data. 
Control Chart: Tinggi_Siku_Berdiri

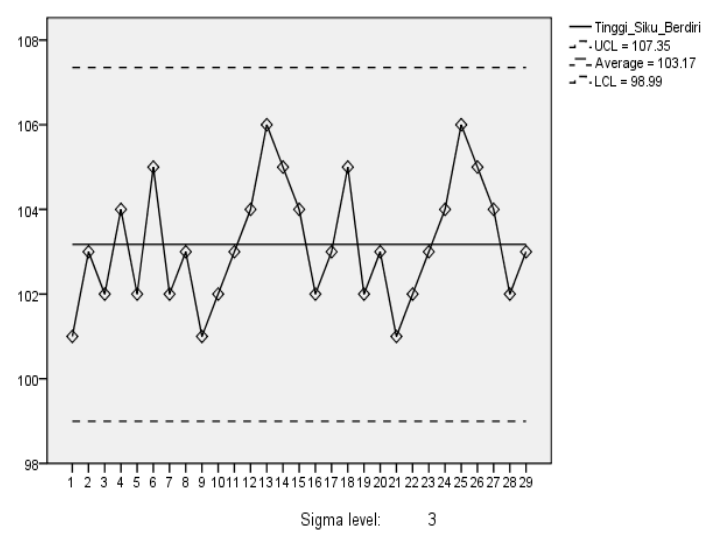

Gambar 3. Hasil Uji Keseragaman Data Tinggi Siku Berdiri

Control Chart: Diameter_Genggam_Tangan

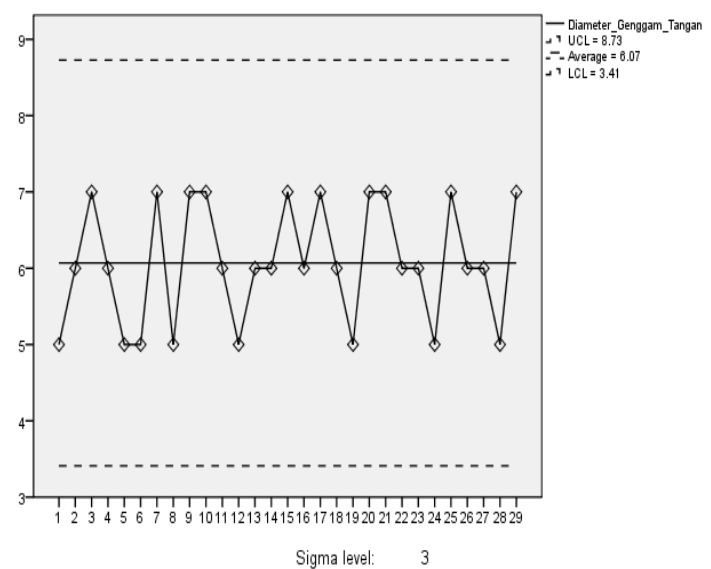

Gambar 4. Hasil Uji Keseragaman Data Diamater Genggam Tangan

\section{Uji Kecukupan Data Antropometri Pekerja}

Uji kecukupan data dilakukan untuk mengetahui apakah data yang digunakan sudah mencukupi atau tidak, yaitu $\mathrm{N}^{\prime}<\mathrm{N}$. Dengan menggunakan tingkat kepercayaan 95\% dan tingkat ketelitian $5 \%$.

$N^{\prime}=\left[\frac{\frac{k}{s} \sqrt{N\left(\sum_{j=1}^{n} x_{j}{ }^{2}\right)-\left(\sum_{j=1}^{n} x_{j}\right)^{2}}}{\left(\sum_{j=1}^{n} x_{j}\right)}\right]^{2}$
Dari hasil uji kecukupan data (Tabel 4) diperoleh hasil bahwa rata-rata data yang dipakai telah memenuhi syarat. Hasil pengamatan yang dilakukan dianggap cukup untuk dilanjutkan ke langkah selanjutnya.

Tabel 4. Uji Kecukupan data.

\begin{tabular}{lcc}
\hline Data Antropometri & N & N' \\
\hline $\begin{array}{l}\text { Tinggi Siku Berdiri } \\
\text { Diameter Genggam } \\
\text { Tangan }\end{array}$ & 30 & 0,3 \\
\hline
\end{tabular}

\section{Mengitung Nilai Persentile}

Proses perancangan alat pengangkut trolly menggunakan data persentil responden yang berjumlah 30 orang berdasarkan nilai persentil yang digunakan. Persentil 50 merupakan ukuran rata-rata tinggi trolly sesuai dengan ukuran ratarata responden [1]. Persentil 5 merupakan ukuran genggaman tangan terkecil responden dengan asumsi jika responden yang paling kecil bisa memegang, maka responden yang lain juga mampu melakukannya [19],

Untuk persentile $\mathrm{P}_{5}$

$\mathrm{P}_{5}=\bar{x}-1,645 \sigma$

Untuk persentile $50^{\text {th }}$

$\mathrm{P}_{50}=\bar{x}$

Untuk persentile $95^{\text {th }}$

$\mathrm{P}_{95}=\bar{x}+1,645 \sigma$

Tabel 5. Nilai Persentile

\begin{tabular}{|c|c|c|c|}
\hline \multirow{2}{*}{$\begin{array}{c}\text { Data } \\
\text { Antropometri }\end{array}$} & \multicolumn{3}{|c|}{ Persentile $(\mathrm{cm})$} \\
\hline & $5-^{\text {th }}$ & $50-^{\text {th }}$ & $95^{\text {th }}$ \\
\hline $\begin{array}{l}\text { Tinggi Siku } \\
\text { Berdiri }\end{array}$ & 100,81 & 103,17 & 105,54 \\
\hline $\begin{array}{l}\text { Diameter } \\
\text { Genggam } \\
\text { Tangan }\end{array}$ & 4,77 & 6,07 & 7,36 \\
\hline
\end{tabular}

\section{Ukuran Troli Ergonomi}

Ukuran yang digunakan untuk merancang troli ergonomi adalah berdasarkan perhitungan dari nilai persentile. Untuk ukuran tinggi troli ergonomi digunakan berdasarkan nilai dari persentile $50^{\text {th }}$, untuk ukuran diameter pegangan tangan troli ergonomi digunakan berdasarkan nilai dari 
persentile $5^{\text {th }}$ (Tabel 5). Adapun untuk ukuran Panjang dan lebar troli ergonomi digunakan berdasarkan ukuran panjang dan lebar karung beras. Hasil keseluruhan ukuran troli ergonomi dapat dilihat pada Gambar 4.

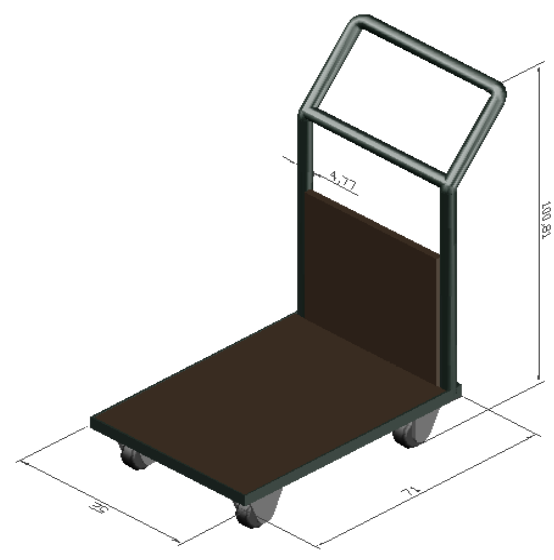

Gambar 4. Troli Ergonomi

Aplikasi Troli Ergonomi terhadap Posisi Kerja Penggunaan troli ergonomi pada aktivitas pengangkutan beras di penggilingan padi dapat memperbaiki posisi kerja dapat dilihat pada gambar 5. Pekerja tidak mengangkat atau memegang pada saat memindahkan gabah. $\mathrm{Hal}$ ini berdampak pada pengurangan beban kerja pada punggung, leher dan pinggang.

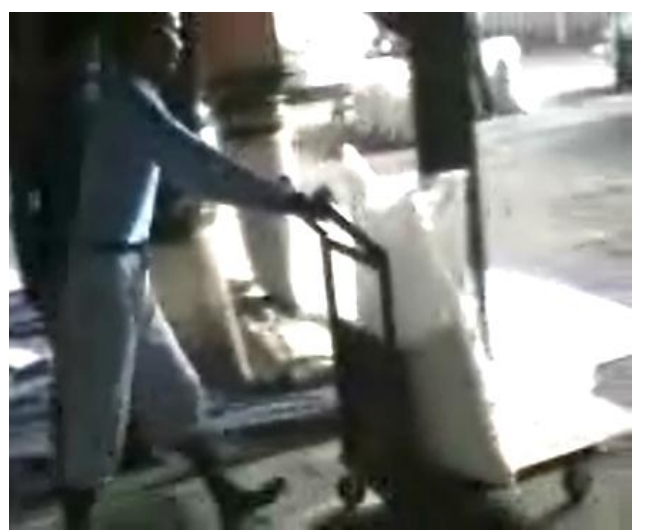

Gambar 5. Aplikasi Troli

Penggunaan alat bantu trolly secara aplikasi mampu membantu meringankan beban pekerja. Berdasarkan hasil kuisioner yang dilakukan diperoleh penurunan keluhan sakit punggung dari 30 responden menjadi 1, keluhan sakit leher dari 28 responden menjadi 3 responden dan penurunan keluhan sakit pinggang menjadi 2 responden dari 25 keluhan. Alat bantu ini belum mampu menurunkan beban lengan dimana dari hasil kuisioner hanya terjadi penurunan satu responden (tabel 7).

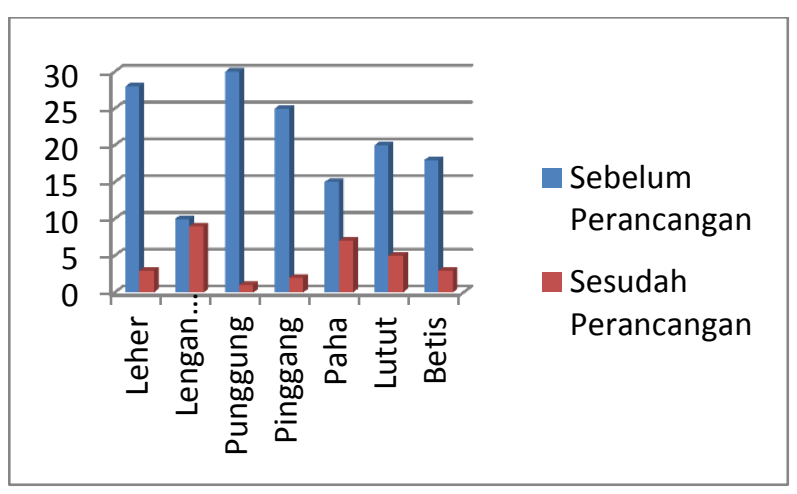

Gambar 7. Grafik perbandingan keluhan sebelum dan sesudah aplikasi troli ergonomi

\section{KESIMPULAN}

Dari pengolahan data yang dilakukan diperoleh hasil perancangan troli ergonomi dengan ukuran tinggi troli 100, $81 \mathrm{~cm}$; diameter genggam tangan troli $4,77 \mathrm{~cm}$; panjang troli $71 \mathrm{~cm}$; dan lebar troli $52 \mathrm{~cm}$. Posisi kerja pengangkut beras lebih nyaman karena menggunakan troli ergonomi, hal ini dibuktikan dengan terjadinya penurunan keluhan pada pekerja pengangkut beras berdasarkan hasil kuisioner terutama pada keluhan punggung dari 30 pekerja menjadi hanya 1 pekerja. Penelitian ini dapat dilanjutkan pada perancangan trolly yang mampu menurunkan beban pada lengan tangan.

\section{DAFTARPUSTAKA}

[1] E. Nurmianto, Ergonomi, Konsep Dasar dan Aplikasinya. Surabaya: Guna Widya, 2004.

[2] P. Carayon, "Human factors of complex sociotechnical systems," Appl. Ergon., vol. 37, no. 4, pp. 525-535, 2006.

[3] J. Dul et al., "A strategy for human factors/ergonomics: developing the discipline and profession," Ergonomics, vol. 55, no. 4, pp. 377-395, 2012.

[4] S. Wignjosoebroto, Ergonomi, Studi Gerak dan Waktu: Teknik Analisis untuk Peningkatan Produktivitas Kerja. Surabaya: Guna Widya, 2000.

[5] S. H. A. Tarwaka and L. Sudiajeng, Ergonomi untuk keselamatan, kesehatan kerja dan produktivitas. Surakarta: UNIBA, 2004.

[6] M. Wynn, "Room to move Critical success factors for an ergonomics initiative," Ind. Eng., vol. 40, no. 6, pp. 47-52, 2008.

[7] M. Ahmadi, S. A. Zakerian, H. Salmanzadeh, and A. Mortezapour, 
"Identification of the Ergonomic Interventions Goals from the Viewpoint of Ergonomics Experts of Iran using Fuzzy Delphi Method," Int. J. Occup. Hyg., vol. 8, no. 3, pp. 151-157, 2017.

[8] V. Vitriyani, P. Pangaribuan, and A. S. Wibowo, "Perancangan Smart Trolley Menggunakan Sensor Imu (inertial Measurement Unit) Berbasis Kendali Pi," eProceedings Eng., vol. 4, no. 3, pp. 3325-3331, 2017.

[9] A. Sokhibi and W. H. Sugiharto, "Perancangan Kursi Ergonomis Untuk Mengurangi Keluhan Pembatik Pada UKM Batik Alfa Shoofa Kudus," in Seminar Nasional SENDI Unisbank, 2018, pp. 21-27.

[10] D. Y. Susilo and H. Prastawa, "Usulan Perbaikan Postur Kerja Tenaga Kerja Pengangkutan Sweet Whey Powder di Gudang Penyimpanan Dengan Metode Ovako Work Posture Analysis System (OWAS).(Studi Kasus di CV. Cita Nasional)," Ind. Eng. Online J., vol. 6, no. 4, pp. 1-8, 2018.

[11] D. Herwanto, A. Purnama, A. Prianto, and K. Adi, "Perbaikan Workstation di PT. Yushiro Indonesia untuk Mengurangi Resiko Keluhan Muskuloskeletal," J. Teknol., vol. 8, no. 2, pp. 71-75, 2016.

[12] F. Yuamita and R. A. Sary, "Usulan Perancangan Alat Bantu Untuk Meminimalisir Kelelahan Fisik dan Mental Pekerja," J. IIm. Tek. Ind., vol. 15, no. 2, pp. 127-138, 2017.

[13] R. D. Astuti, S. Susmartini, and A. P.
Kinanthi, "Improving the work position of worker based on manual material handling in rice mill industry," in $A I P$ Conference Proceedings, 2017, vol. 1902, no. 1, p. 20043.

[14] B. P. T. Nugroho, I. Iftadi, and T. Rochman, "Usulan Rancangan Troli Sebagai Alat Bantu Angkut Karung Gabah Dalam Rangka Perbaikan Postur Kerja di Penggilingan Padi (Studi Kasus: Penggilingan Padi di Sragen)," PERFORMA Media IIm. Tek. Ind., vol. 12, no. 1, 2013.

[15] J. Chang, K. Jung, J. Hwang, Y. Kang, S. Lee, and A. Freivalds, "Determination of bicycle handle diameters considering hand anthropometric data and user satisfaction," in Proceedings of the Human Factors and Ergonomics Society Annual Meeting, 2010, vol. 54, no. 20, pp. 1790-1793.

[16] A. Luximon, Y. Zhang, Y. Luximon, and M. Xiao, "Sizing and grading for wearable products," Comput. Des., vol. 44, no. 1, pp. 77-84, 2012.

[17] D. Lacko et al., "Ergonomic design of an EEG headset using 3D anthropometry," Appl. Ergon., vol. 58, pp. 128-136, 2017.

[18] U. Sekaran, Metodologi penelitian untuk bisnis. Jakarta: Salemba Empat, 2006.

[19] R. Alojado, B. Custodio, K. M. Lasala, and $P$. L. Marigomen, "Designing an ergonomic chair for pedicurists and manicurists in Quezon City, Philippines," Procedia Manuf., vol. 3, pp. 1812-1816, 2015. 